\section{O DIREITO COMERCIAL E A SUA UNIDADE}

\section{Adamastor Lima}

Catedrático da Faculdade de Direito do Rio de Janeiro e Membro correspondente do Instituto Argentino de Derecho Comercial e do Instituto de Derecho Compa. rado do Mexico.

1 - As preocupações que, na vida universitária, nos absorvem o espirito - e que, por vêzes, nos empolgam - parecem levá-lo para regiões desconhecidas de abstrações sucessivas, onde a sublimidade impera e a inteligência brilha. Tendência nobilitante, sem dúvida, pois revela, a um tempo, propósitos alevantados de aperfeiçoamento e esforços, louváveis, para alcançá-lo.

A vida universitária brasileira, com êste Congresso Jurídico que a Faculdade de Direito de Pôrto Alegre promove, dá ensêjo a reflexões essencialmente úteis à própria vida social.

Cumpre recordar que o alvo permanente das atenções nossas e alheias - é o homem, com as suas necessidades de tôdas as ordens, da religiosa à econômico, e que as realizações para satisfazê-las fazem um complexo, que não se pode inventariar e que vai aumentando a olhos vistos.

2 - As conjunturas - que inspiraram e, por vêzes, impuseram essas realizações - levaram os estudiosos a inventar uma palavra genérica como aquela, que abrangesse o todo conquistado, pondo a sua vantagem intrínseca em evidência plena. Assim, às necessidades correspondem as utilidades e estas serão coisas - o que existe ou pode existir - e pessoas, na relação de servir.

Pena é que essas noções pareçam abandonadas em certos instantes em que deveriam ser encarecidas e o espírito se empenhe na obtenção, alhures, de esclarecimentos que só podem ser colhidos nos quadros movediços da vida real.

Dessa observação, poderemos tirar a prova do esfôrço constante para que fiquem, pelas pesquisas em tôdas as direções, desvendadas as causas dos fenômenos sociais.

Mas a Economia tomou o seu lugar entre as grandes fôrças de agregação da sociedade e os seus princípios gerais já não podem ser ignorados. Sofre, entretanto - ela também - de certas falhas na sua apreciação, merecendo destaque a assinalada pelo Professor $\mathrm{Mi}$ guel Garáu nestas linhas simples na aparência e profundas nas conseqüências:

“... na época da máquina, esqueceu-se que, em tôdas as. manifestações do trabalho, o Homem é o elemento fundamental. A máquina e a ferramenta são, apenas, meios complementares e, por isso, se queremos que a máquina produza, é o Homem que há-de ser o objeto principal dos nossos cuidados" $\left({ }^{1}\right)$.

Eis aí positivada a ligação necessária entre a Economia e 0 Direito, ao qual incumbe, essencialmente, preservar, de cada um, a liberdade e a propriedade, na obra do Progresso, ingente e interminável.

3 - Avultam as utilidades, cujo conceito - já por si tão amplo - parece até não bastar para aplicar-se o vocábulo a tudo quanto as necessidades humanas - individuais e coletivas - num crescendo imenso, vão reclamando. Mantém-se, porém, a expressão, com o seu velho prestígio, e as diferenciações que o progresso científico realiza só lhe subtraem à aplicação as pessoas, cuja dignidade social é uma conquista do espírito moderno.

Como, porém, as realizações, da Ciência ou da Técnica, não são acompanhadas, no mesmo ritmo, pela linguagem, torna-se mister atentar muito no sentido que cada palavra pode ter dentro de uma determinada natureza de relações sociais.

Nessa ordem de idéias foi que ressaltámos em nossa Introdução ao Direito Comercial que o vocábulo trabalho tem quatro significados distintos - energia humana, emprêgo adequado, ação específica e coisa produzida $\left({ }^{2}\right)$.

Aos Juristas - mais que a outros quaisquer - cumpre estar permanentemente alerta, a fim de que não se confunda a energia humana com o seu titular, para que não desapareça a liberdade.

Restringe-se, dessarte, o âmbito das utilidades pela diferen ciaça imprescindivel entre a energia humana è o seu titular, constituída a sociedade de pessoas que se respeitam reciprocamente.

4 - Todos - pouco importa a sua condição - precisam de possuir alguma coisa, carecem da propriedade, ainda que para uma vida modesta e obscura.

Nessa consideração - tão singelas quanto a de Garáu - desponta a importância do Comércio para a transferência pacífica do domínio das coisas e a prestação - pacífica também - de serviços destinados à satisfação das necessidades individuais ou coletivas.

Traduz um sentimento enraizado na convicção de cada pessoa que queira refletir a figura literária ou a representação de qualquer outra arte que dá ao Comércio o papel de Arauto do Progresso. 
Tudo isso reclama, porém, organização e atividades, cujas linhas difìcilmente são fixadas e cujos extremos jamais serão atingidos.

O Comércio - êle mesmo - para o seu exercício, ou no seu exercício, já consagrou modos de proceder que exigem compreensão especial e respeito absoluto. É que, de arte, já se fêz ciência.

5 - $\mathrm{Na}$ atividade mercantil, vão surgindo, como que numa aparição caleidoscópica, obstáculos a vencer.

Afora os interêsses pessoais, sempre expostos a conflitos de tôda sorte - que o Direito procura prevenir ou resolver - existem os do próprio Comércio, os quais reclamam normas, regras de consistência social, tanto vale dizer de natureza jurídica.

Situados no próprio ambiente físico, em que o Comércio ha-de fazer sentir a sua atividade, podemos notar fàcilmente os referidos obstáculos. E, nessas condições, êle se apresenta como Comércio Terrestre, Comércio Marítimo e Comércio Aéreo, na estrutura jurídica de seus órgãos e organismos, bem como pela disciplinação do seu funcionamento.

E o que devemos tornar bem nítida é a circunstância de ser a ação comercial dominada por princípios que lhe atestam a unidade, pouco importando o meio físico de que haja mister para concretizar-se ou em que haja de ser exercida. Será sempre uma intermediação realizada com o emprêgo de capital. pois o comerciante tem de comprar para vender, visando ao lucro, que é, dêsse capital, um acréscimo.

Verificamos a evolução do Comércio nas suas fases da Troca, da Moeda e do Crédito, nesta se lhe abrindo um horizonte vastíssimo, opondo-lhe novos obstáculos, vencidos com os velhos princípios, que lhe têm assegurado um engrandecimento a bem dizer ilimitado.

6 - Em qualquer uma dessas duas ordens de obstáculos, das de espaço ou de tempo, representou sempre o Direito - ainda quando sem a autoridade estatal - para o Comércio, a base mesma da sua vida. E muito mais do que outrora, nos tempos atuais, que se caracterizam pela jurização crescente das relações humanas, deve o Direito, na sua missão social, proporcionar ao Comércio a garantia indispensável.

7 - Falar no Direito é pensar no Jurista, e êste - Professor, Magistrado ou Advogado, pouco importa a atuação que lhe caiba - no dizer de Luiz Francisco Rabello,

"sob pena de cair num abstracionismo improfícuo, não se pode desligar da Realidade, por que tem de mover-se no Mundo das Realidades, entre Realidades" $\left(^{3}\right)$.

Já lembramos que, no pentaedro Religião, Moral, Política, Direito e Economia, com os seus estudos bastante desenvolvidos, estão as expressões das cinco fôrças de agregação social, ligadas entre si sòlidamente, cada uma com finalidade idêntica à do Direito e servindo às relações sociais, para serem possíveis a convivência humana e o progresso contínuo ( 4 ).

Tais elementos ficaram no Passado e, para muitos, ainda vivem hoje confundidos. Entre êles operou-se, entretanto, a diferenciação, verificando-se, de todos, a expansão impressionante.

8 - Destacando, agora, o Direito, para o fim que colimamos, ocorrem-nos as conhecidas observações de William James e fixamos, com o filósofo, que

"o espírito e os princípios da Ciência são meras questões de metódo; não há nada nêles que possa impedir à Ciencia de tratar, com êxito, de um Mundo, no qual as fôrças pessoais são o ponto de partida de efeitos novos" $\left({ }^{5}\right)$.

Tem, ao nosso ver, cabimento na matéria jurídica a assertiva de Liard de - como o sonhara Descartes - a Ciência da Natureza não se constitui a priori pois as leis são realizadas nos fatos e nestes, exclusivamente nestes, é que se faz mister procurá-las, concluindo que, dos fatos, precisamos inferi-las por meio da observação e da experimentação $\left({ }^{6}\right)$. E sem perder de vista o caráter subsidiário desta, relativamente àquela é que isso afirmamos $(7)$. Não remos, talvez, longe de concordar com Georges Renard, em sua erudita conferência da Faculdade de Direito de Nancy (França), em $10^{\circ}$ de dezembro de 1924, quando proclamou que

"o Direito é uma arte, fundada numa Ciência" $\left({ }^{8}\right)$.

Considerado assim, notamos, a cada instante, o esfôrço para a análise que decompõe, sem ser seguido de um outro para a sintese,
que compóe.

Vivemos, todavia, numa época em que é preciso compor, construir.

Se no aforismo francês, nenhum esfôrço é inútil, os que, depois da 2.a Guerra Mundial, se fizeram para as construções jurídicas hão de despertar, pelo menos, um sentimento de simpatia.

- E haverá, pelo trabalho intelectual, sinceramente executado, um prêmio maior?

As próprias críticas, tão fáceis de fazer, quando os seus autores procuram destruir e revelar, apenas, a profunda erudição possuída, valem muito, fazendo o papel da chuva que se arremessa sôbre a parede pintada: permite verificar-se, afinal, a qualidade da tinta
empregada... $16-$ R. D. $1 .^{\circ}$ Vol 
Ouvimos falar sempre na Ciência Jurídica, mas somos forçados a reconhecer que, a tantas e tão freqüentes referências, não corresponde a produção dos escritores.

Copograssi, na Itália, fazendo um livro sôbre o Problema da Ciência do Direito, refere a experiência jurídica e acaba com apelos à Filosofia... $\left({ }^{9}\right)$.

A distinção entre a Ciência e a Filosofia está, entretanto, no conhecimento geral.

Adolfo G. Posada, traduzindo a obra de Savigny, que denominou $D e$ la vocación de nuestro siglo para la legislación e la ciencia del derecho, adotou o título da edição francesa, mas, o editor esclareceu que êle traduziu

"jurisprudence por ciência do direito, têrmos sinônimos na linguagem jurídica, conquanto seja mais clássico o primeiro e mais compreensivo o segundo" $\left({ }^{10}\right)$.

9 - Esse assunto não se inclúi - cumpre-nos frisar - entre os que permanecem no âmbito universitário, sem interêsse alhures

A nossa lei de Introdução do Código Civil (11) reproduziu, no Art. $4 .^{\circ}$, a referência que fazia a anterior, no Art. $7 .^{\circ}$, aos princípios gerais do Direito. Tais princípios hão-de ser a base da Ciência Jurídica e a extração dêles, no dizer do Eminente Luiz da Cunha Gonçalves - Professor Honorário de Faculdades de Direito do Brasil,

"não é fácil tarefa" $\left.{ }^{12}\right)$.

Assim pensou também o nosso - muito nosso e nunca assaz louvado Clóvis Beviláqua - que revelou a fonte direta do aludido. Art. $7 .^{\circ}$ - o Código Italiano - aduzindo que

"na Itália, os princípios gerais do Direito foram interpretados, diferentemente, pelos autores" $\left({ }^{13}\right)$.

Del Vecchio - para citar dêles um apenas - achou que tais princípios são as verdades superiores do Direito, in genese, os seus fundamentos lógicos e até morais.

Iríamos longe e nos desviaríamos do tema escolhido se nos de morássemos nas opiniões brilhantes, emitidas a respeito, apreciando-as.

Preferimos, por isso, render a homenagem que julgamos devida sempre ao inolvidável Clóvis Beviláqua, invocando o seư augusto pensamento:
"Não se trata, como pretendem alguns, dos princípios gerais do direito nacional, mas, sim, dos elementos fundamentais da cultura jurídica humana em nossos dias; das idéias e princípios, sôbre os quais assenta a concepção jurídica dominante; das induções e generalizações da ciência do direito e dos preceitos da técnica.

Êsses princípios, objetam, são vagos, indeterminados. Mas não é tanto assim. Certamente temos de penetrar fundo na Filosofia do Direito, na História da $\mathrm{Ci}$ vilização, e ter o espírito aparelhado por uma educação jurídica bem cuidada, para empreendermos a investigação dos princípios gerais do direito. Mas êsse mesmo preparo mental indica a rota a seguir, e habilita o jurista a reconhecer a natureza positiva das coisas, elemento objetivo, impreciso, mas fecundo da investigação jurídica, segundo Gény, fonte subsidiária do direito, que tem por fundamento o postulado seguinte: "os elementos de fato de tôda organização jurídica trazem em si as condições de seu equilíbrio e, por assim dizer, descobrem' espontâneamente, a norma que os deve reger". $\left({ }^{14}\right)$.

Com o aviso de Cunha Gonçalves e essas ponderações de Clóvis Beviláqua, seria razoável prosseguirmos em nosso trabalho.

Já fizemos, entretanto, afirmativas que nos deixam à vontade para oferecer a todos, aos aludidos críticos inclusive, o contingente das nossas meditações.

Entendemos que a obra universitária não deve ser apenas a contemplação do passado, mas obra atual, viva e de utilidade coletiva.

Ao que pudemos apurar, os citados princípios gerais são cristalizações de caráter universal, que estão na base do Direito, em seu aspecto científico.

Como tais, temos cinco princípios, que enunciamos na ordem seguinte:

I) Classificação

$$
\begin{array}{ll}
\text { II) } & \text { Igualação; } \\
\text { III) } & \text { Vinculação; } \\
\text { III) } \\
\text { IV) Conservação; e } \\
\text { V) } \text { Compelição. }
\end{array}
$$

O Direito faz a sua contribuição para a Ordem Social, classificando, igualando, vinculando, conservando e compelindo.

Fenômeno profundamente humano, haveria de acomodar-se a tôdas as relações sociais, não para embaraçá-las, mas para garanti-las e, mesmo, facilitá-las. 


\section{$-240-$}

10 - Muito cedo, mais do que talvez possamos demonstrar, - Comércio, feito ordenadamente, criou a Prática Comercial, que é

"a realização dêle, sob o ponto de vista do seu exercício, tomado no conjunto de troca de produtos e prestação de serviços" ( $\left.{ }^{15}\right)$.

e, após um esfôrço continuado, que durou séculos e séculos, a penetração jurídica fêz nascer, para viver, lado a lado, com o Direito Civil, o Direito Comercial.

11 - Direito - Ciência ou Arte, mais na condição desta que na daquela - veio empolgando os espíritos até hoje pela compelição, que lhe é ínsita, e que faz com que o seu titular permaneça vigilante, para identificá-lo e defendê-lo, armando-o, simultâneamente, de meios para conseguir, do Poder Público, as medidas adequadas à respectiva efetivação social. Compele, pois, o seu próprio titular e permite que êste faça compelir terceiros ao respeito que todos lhe devemos.

Ihering, na sua famosa conferência, tornou patente, do Direito, a fôrça exuberante.

Levado, que foi, em especialização, à vida mercantil, o Direito teria de respeitar os já mencionados objetivos do próprio Comércio.

Por isso, foi que a atuação jurídica nas relações comerciais teve, como ocorreu com as célebres Ordenanças de Colbert - a de 1673 e a de 1681 - o cunho de elemento valioso.

O fenômeno jurídico é de tanta sutileza que se enforma de tôdas as manifestações verificadas na sociedade.

Assim, o mar, ensejando a Navegação, fêz despertar no engenho humano a preocupação pelos meios técnicos convenientes ao exercício do Comércio, com segurança e proveito.

No exame dos fatos através dos tempos, precisamos ter bem patente que foi o Comércio que deu vida e desenvolvimento à $\mathrm{Na}$ vegação. Um e outra nas cogitações jurídicas, teriam, como tiveram, normas e regras condizentes com as respectivas finalidades.

O Código Comercial Francês - o avô dos Códigos - acolhendo as referidas Ordenanças, fêz obra de lógica.

Havia o Comércio, que se exercia em dois ambientes físicos, cada qual com as suas normas e regras e não um Comércio de Terra e um outro Comércio de Mar.

A ação comercial não deveria ter o princípio da sua unidade sacrificado pelo seu tratamento legal.

Muito faz, todavia, a abstração que certos Juristas festejam tanto. Aí vemos os trabalhos eruditos que nos apresentam, não, apenas, o particularismo do Direito Marítimo, mas as notícias de um Direito da Navegação, ou Navegacional, como sustentou sau- doso professor brasileiro. Outros, generalizando ainda mais, pretendem um Direito dos Transportes - terrestre, marítimo e aéreo.

É que o domínio dos ares, para fins comerciais, levou alguns Juristas a substimar a Técnica de Comerciar e a dar relêvo à Técnica de Transportar. Não repararam que ao serviço do Comércio é que está o transporte, desta ou daquela espécie. Não distingüíram, substancialmente, o principal do acessório.

Se o tivessem feito, essa dependência os levaria à convicção de que ambos são partes de um todo. Essa unidade econômica é manifesta.

$\mathrm{O}$ que fôr feito para um, deve tomar na devida conta os imperativos técnicos do outro.

12 - O Direito não deverá, por isso, seguir critério que favoreça a inversão da ordem das coisas; terá de ver o fenômeno comercial preponderante.

A programação do Ensino do Direito Comercial nas Faculdades de Direito do Brasil foi sábia, portanto. O estudo da parte relativa ao tratamento do Comércio Terrestre (3. ${ }^{\circ}$ Ano) antecede a pertinente ao Comércio Marítimo e ao Aéreo (4. ${ }^{\circ}$ Ano). As linhas gerais, fixadas a princípio, ficarão dominando até o fim. Se as imposições do ambiente físico exigiram da Técnica contribuições que hajam de refletir-se na regulação jurídica do Comércio, para que não se desnature o escopo de comerciar, o entendimento disso dar-se-á com as devidas cautelas.

Nunca como principal será havido o acessório, êste jamais perderá a sua categoria.

Eis o que, na aludida orientação didática, vemos bem claro. Vemos e aplaudimos.

13 - As considerações que acabamos de esboçar habilitam a compreender que vários Juristas - a cujos trabalhos rendemos as homenagens merecidas - em presença das realizações maravilhosas da Navegação e da Aviação e, atribuindo às emanações das soberanias nacionais um efeito destorcivo e não raro deletério na vida comercial, em holocausto ao Direito das Nações, tendo partido do Direito Comercial Marítimo no seu apregoado particularismo, chegaram a um Direito Marítimo, com situação no Direito Público e no Direito Privado.

Brindam-nos, então, com um Direito Marítimo subdvidido em Direito Marítimo Internacional, Direito Marítimo Administrativo e Direito Marítimo Privado, acrescentando - ou Direito Comercial Maritimo ( $\left.{ }^{16}\right)$

Temos o hábito de lembrar que as classificações - sejam elas quais forem - não passam de artifícios para facilitar o conhecimento das coisas. São andaimes para a construção a fazer-se. Pro- 
curamos assim conservar a atenção no que é fundamental $e$ simultâneamente, na apreciação dos fenômenos, preservar a liberdade espiritual.

Pelo que acabámos de frisar, essa classificação, destacando um Direito Marítimo, onde o Direito Comercial vai figurar, apenas, como parte aliquanta, perturba a visão dêste ramo jurídico, em tôda a sua importância.

Para impugná-la, poderíamos levantar, desde logo, a preliminar de que o Direito é realização essencialmente nacional e não é pela sua tendência à universalização, de que tão eruditamente, declarando estar então o mundo numa... "hora febril" tratou o Prof João Monteiro ( ${ }^{17}$ ) - glória da Universidade de São Paulo e do Brasil - que, nesta oportunidade, êle nos deve impressionar.

Preferimos, porém, ressaltar o que Silva Costa - Mestre eminente de tantas gerações de juristas Brasileiros - escreveu no $D$ i reito Comercial Marítimo, livro que já desfruta, assaz merecidamente, o privilégio de obra clássica. Para êsse autor,

O Direito Maritimo Internacional trata da liberdade dos mares, em princípio, dos direitos e obrigaçóes entre beligerantes e neutros, assim como das questões conexas.

O Direito Marítimo Administrativo regula a polícia dos portos, a inscrição marítima, as instituições da Marinha Mercante, o regime sanitário e contribuições masrítimas.

O Direito Maritimo Privado ou Direito Comercial Marítimo ocupa-se com os contratos marítimos e instituições que a êles se prendem".

E é o próprio renomado autor com as linhas, com que apresenta essa classificação, quem evidencia o critério que foi por êle acolhido e que não podemos aceitar.

"O Direito Marítimo - escreveu - em sua significação mais genérica, regula as relações jurídicas da na vegação marítima, podendo receber a tríplice classificação seguinte" $\left({ }^{18}\right)$.

O Mestre preferiu, ao invés do Comércio Marítimo - Código Comercial Brasileiro na 2. ${ }^{2}$ Parte, - fixar a Navegação Marítima.

Não devemos pensar que a sua obra, editada em 1899, recolheu diretrizes que o espírito jurídico de alguns não tenha sancionado.
Almáquio Diniz - Professor da Faculdade de Direito da Bahia, que tanto dignificou, com proveito, para a cultura nacional - se fêzz eco, no Brasil, do particularismo do Direito Comercial Marítimo, enaltecendo um dos seus grandes defensores - o Prof. Julien Bonnecase, da Faculdade de Direito de Bordeaux (França) - atingindo prontamente, com a fôrça da lógica, um ponto tão alto, que Bonnecase indicara tão-sòmente:

"O navio - sustentou - não pode, enquadrado no campo de estudo de tal ciência (referia-se ao Direito Marítimo, com as subdivisões que acabamos de mencionar) ser encarado fora das relações que constituem a vida internacional da Humanidade. É preciso que se tenha uma noção positiva do caráter jurídico do mar, a qual há-de corresponder, necessàriamente, à noção física, tal como tem sido fixada pelas ciências naturais, para que se realizem todos os casos particulares da noção jurí dica do navio, no mundo internacional. Daí a conclusão de que há, no que concerne à navegação, uma espécie de harmonia estabelecida, entre o lugar onde ela se exerce - oceano, mar ou rio - e o instrumento com o qual ela se exerce - navio ou barco" $\left({ }^{19}\right)$.

E concluiu ainda, incisivamente:

"O reconhecimento internacional do navio é a melhor particularização do Direito Comercial Marítimo.

$\mathrm{E}$ isto, que não está senão em traços gerais, com promessa de desenvolvimento e em lugar próprio, na obra do Prof. Julien Bonnecase, é a sua maior originalidade a concluir-se neste momento, como vamos concluindo, no qual a facilidade das navegações marítimas encurtando, sobremodo, as distâncias, desfaz as fronteiras e abre os portos ao internacionalismo comercial" $\left({ }^{20}\right)$.

Almáquio Diniz, com quem tivemos a ventura de privar, proclamou, nesse trabalho, o navio pessoa de direito internacional público. Não ficou na individualidade, conferiu-lhe a personalidade e - situou no Direito Internacional Público.

Se a aludida classificação e os estudos feitos objetivam o entendimento das realidades econômicas, com a surpressão do navio do campo do Direito Comercial - centro que êle é de tantas preocupações mercantis e instrumento do comércio por mar - êsse entendimento ficou gravemente comprometido. 
Dessa reflexão o que resulta é que as afirmativas, há pouco apresentadas sôbre o Comércio e a Navegação, têm procedência. São procedentes e necessárias para que o Jurista não seja levado a conclusões que mutilariam o Direito Comercial, retirando-lhe o Navio, quando a sua importância econômica, as suas peculiaridades. originaram institutos jurídicos de Direito Privado de tanto relêvo e serviram de modêlo a realizações do Direito Aéreo e, ao nosso ver, poderão inspirar, se já não o fizeram - linhas jurídicas de vera utilidade para a emprêsa comercial, que já não pode ter negada a sua projeção na vida do Comércio.

Se insistíssemos na ordem na idéia em que a Navegação se exalta, acabaríamos com o Direito Comercial Marítimo que nem seria subdivisão do Direito Comercial. Encontraríamos um Direito Comercial Aéreo de características idênticas e, com tal orientação, as normas e regras jurídicas que extraíssemos serviriam mais para confundir que para esclarecer.

O Comércio - como procuramos evidenciar - guarda no fundo de tôdas as suas atividades, por mais complicadas que se apresentem à apreciação geral, uma unidade econômica, que é o segrêdo do seu prestígio.

O Direito, os Juristas precisam atentar nisso, para que lhe possam dar as contribuições esperadas.

Ainda uma vez - uma vez mais - patenteia-se que os Juristas. devem viver no Mundo das Realidades.

14 - Comércio e Direito Comercial juntos como estão na ordem social, hão-de manter-se na ordem jurídica.

$\mathrm{O}$ assunto está pôsto assim no Código de 1850. E a despeito de quaisquer reservas doutrinárias, a orientação prevaleceu para leis complementares.

15 - Tenhamos, porém, na devida conta que tudo quanto acabamos de escrever não implica em só admitir um Código para o Comércio, com três partes distintas.

A orientação doutrinária é que deve prevalecer.

Os legisladores poderão resolver o Problema da Codificação elaborando códigos separados.

Uma coisa é a Ciência Jurídica outra a Ciência Legislativa e ambas, colimando facilidades para a vida individual e coletiva, consideram as matérias de que se ocupam atentas à Economia, à Moral, à Política, à própria Religião, no que tôdas essas fôrças de agregação social ofereçam para a harmonia da Sociedade.

16 - Sendo o Comércio a intermediação lucrativa, temos de aḍitir a especulação $\left({ }^{21}\right)$ e o lucro $\left({ }^{22}\right)$.

O comerciante precisa do capital com o que paga o que compra para revender e deve agir especulativamente para atingir o fim lu- crativo. Os obstáculos que se lhe apresentem, de espaço ou tempo, precisam ser vencidos com as contribuições da Ciência e da Técnica.

Vemos, em tôda a atividade comercial, um sentido de unidade, presente e atuante.

A Economia e, na sua essência, a relação entre uma necessidade e uma coisa, à qual se atribui, por isso, utilidade - relação que, no dizer de Garelli, é a própria utilidade $\left({ }^{23}\right)$.

A correlação entre necessidades $e$ utilidades encontra no Comércio o meio da sua manifestação social.

Da Economia onde é dominante - transmite-se ao Comércio, lògicamente, o princípio da unidade.

Juridicamente considerado êsse assunto, distinguimos problemas de Direito e problemas de Comércio, uns e outros com bases científicas. E, pela sua finalidade, como pela natureza mesma do Comércio, o Direito Comercial - com fisionomia própria no Quadro Geral da Matéria Jurídica - há-de apresentar um caráter de unidade.

Pelo exposto, apresentamos as seguintes

\section{CONCLUSÕES}

1. ${ }^{\mathrm{a}}$ É preciso admitir a existência de uma Ciência Ju rídica e de uma Ciência Comercial, devidamente constituídas, para ser versado, com segurança, o Direito Comercial.

2. $\left.{ }^{2}\right)$ O Comércio tem no transporte um elemento necessário.

3.a) As economias nacionais transmitem ao Comércio um sentido de unidade.

4. ${ }^{a}$ O sentido de unidade do Comércio é acolhido pelo Direito Comercial, que lhe deverá dar expressão. científica.

\section{NOTAS EXPLICATIVAS}

1 - El capitalismo en crisis, p. 56.

2 - Int. Dir. Com., p. 18

3 - Natureza Juridica do Direito de autor, Jornal do Fôro, de Lisboa. $88 / 172$

4 - Introdução ao Direito Comercial, ed. 1948, p. 190

5 - A Filosofia de William James, traid. de Antonio Ruas, p. 104

6 - L. Liard, Lógica, p. 113

7 - L. Liard, Lógica, p. 117 
8 - Le Droit, La Cience e ü’Art, p. 109 (B, 5/1/5)

9 - Giuseppe Capograssi, Il Problema deila Scienza del Diritto, p. 236/237 10 - Editorial Atalaya, Buenos Aires, Argentina, p. 9

11 - Dec.-lei n. 4707 , de 17 de setembro de 1942

12 - Tratado de Direito Civil, $1 / 473$

13 - Có́ảigo Civil, Com. ao Art. 7:0 da Lei de Introdução

14 - Código Civil, Com. ao Art. 7.0 đla Lei de Introdução

15 - Odamastor Lima, Notas de aulas.

16 - Silva Costa, Direito Comercial Marítimo, $1 / 25$

17 - Da futura universalizacão do Direito (Discurso inaugural do Curso de Legislacão Comparada, lido em 30 de maio de 1892).

18 - Idem, ibdem.

19 - 0 Savio - jessoa de direito internacional público, p. 12

19 - Navio -

- Especulacão, têrmo do comércio, não é bem como definiu I. de Soua Duarte uma operação comercial assaz aleatória, cheia de riscos.

22 - Lucro é o capital acrescido.

23 - Alessanidro Garelli, Filosofia del Monopolio, p. 10

\section{RELATÓRIO E PARECER}

\section{Relator: PAULO BARBOSA LESSA}

1 - Trata o eminente professor da Faculdade de Direito do Rio de Janeiro, nome que se tem impôsto aos estudiosos do direito mercantil no pás e no estrangeiro, do problema da unidade do direito comercial. Para chegar às conclusões, hàbilmente extraídas das premissas colocadas, traça o mestre carioca o caminho seguido pela ciência do direito, radicando-a, fundamentalmente, na natureza social do homem. Ressalta as raízes econômicas do problema. Diz das relações entre a economia e o direito. Diferencia, empós, com nitidez o campo da filosofia e da ciência do direito, ressaltando, com Georges Renard, a importância da formulação de uma teoria jurídica, eminentemente científica. Seguindo a linha que, com a obra de Gény, se tornou clássica, salienta a importância prática do problema, face mesmo ao texto da lei brasileira, quando coloca os princípios gerais do direito como fonte de normatividade jurídica. Analisa êsses princípios gerais, discute-os e classifica-os mestralmente. Só, então, penetra na âmago especializado do problema. Realça a fundamental importância que tem o conceito de comércio para o direito comercial. Diz de sua necessidade, mesmo. Compara, por fim, os diversos ramos do direito mercantil, notadamente o terrestre e o marítimo, para concluir que devem manter entre si, tal como acontece na realidade, traço de união íntima, mercê da constatação da relevância da noção de transporte na noção mais geral do próprio comércio.
2 - Nota-se, da simples exposição da tese, a imensa gama de assuntos tocados pelo mestre brasileiro. $O$ assunto deflui de sua concepção, com uma lógica inatacável. Sente-se a segurança da mente que o pensou.

3 - A proposição que ressalta a existência de uma ciência jurídica e de uma ciência comercial é perfeitamente adequada à realidade. Nesses últimos decênios ingente tem sido o esfôrço dos juristas a fim de plasmar a sua ciência, em moldes veramente científicos. Ciência e filosofia não se opõem. Antes se completam. Trata-se de estudar o mesmo fenômeno, empregando métodos diferentes e com diverso objetivo. A preocupação de transformar o direito em verdadeira ciência, extremando a ciência do direito da antiga jurisprudência, tem sido, talvez, a maior contribuição do século para os problemas jurídicos.

4 - Inequívoco o constatar-se a tendência do novo direito comercial em desdobrar-se em porções, cada vez mais específicas, atendendo ao princípio da divisão do esfôrço, e ao seu corolário da divisão da realidade em porções cada vez mínimas, a fim de um melhor tratamento dos problemas. Todo o esfôrço da ciência pode ser resumido no discernir cada vez mais. Discernindo, diferençando o que antes parecia idêntico é que a ciência em geral, e a ciência do direito em particular, tem evolvido para melhor.

5 - Tal constatação se não opõe aos conceitos emitidos pelo professor carioca. De feito, tal minúcia técnica bem se amolga ao reconhecimento de uma unidade na matéria comercial em geral. Pacífico é o reconhecimento de uma fisionomia própria à matéria comercial, compreendida nela u'a maior ou menor cópia de fenômenos. É conhecida a distinção entre autonomia sistemática e autonomia histórica mercantil. O que ressalta no caso constatar é a existência de um comum traço de união entre os diversos ramos do direito comercial, união que é um corolário da contínua presença do fenômeno comércio em todo o campo coberto pelo direito mercantil. Essa união, segundo frisa o mestre, se encontra precìuamente no conceito de transporte, presente em todo o fenômeno econômico do comércio.

6 - Isso pôsto, cabe concluir pela aspiração de um tratamento de unidade jurídica, entendida como unidade de princípios, para tôda a matéria mercantil, respeitada, é certo, a fisionomia de cada ramo do direito mercantil, a ser adotado pelo legislador em sua obra de técnica legislativa.

7 - Recomenda-se a aceitação da tese pelo plenário, considerando-a valioso subsídio para o estudo do problema e para a apreciação técnico-jurídica do legislador brasileiro. 